Final version:

Hingley, M.K., Lindgreen, A., and Casswell, B. (2005), "Supplier-retailer relationships in United Kingdom fresh produce supply chain”, Journal of International Food \& Agribusiness Marketing, Vol. 18, No. 1/2, pp. 49-86. (ISSN 0897-4438)

For full article, please contact LindgreenA@cardiff.ac.uk

\title{
Supplier-Retailer Relationships in the UK Fresh Produce Supply Chain
}

\author{
Mr. Martin Hingley, Harper Adams University College ${ }^{1}$ \\ Dr. Adam Lindgreen, Eindhoven University of Technology ${ }^{2}$ \\ Mr. Brett Casswell, Harper Adams University College ${ }^{3}$
}

\footnotetext{
${ }^{1}$ Mr. Martin Hingley, Department of Business Management and Marketing, Harper Adams University College, Newport, Shropshire, TF10 8NB, United Kingdom. E-mail: mhingley@ harper-adams.ac.uk. Telephone: + 44 (0) 1952820280 . Fax: + 44 - (0) 1952814783.

${ }^{2}$ Address for all correspondence: Dr. Adam Lindgreen, Department of Marketing, Faculty of Technology Management, TEMA 10, Eindhoven University of Technology, Den Dolech 2, P.O. Box 513, 5600 MB

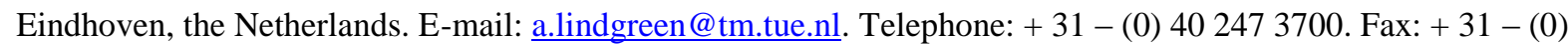
402465949.

${ }^{3}$ Mr. Brett Casswell, Department of Business Management and Marketing, Harper Adams University College, Newport, Shropshire, TF10 8NB, United Kingdom.
} 


\title{
Supplier-Retailer Relationships in the UK Fresh Produce Supply Chain
}

\begin{abstract}
Over the past decade, the UK fresh produce (fruit, vegetables, and salads) supply chain has undergone numerous changes, with retailers becoming increasingly powerful. The overall trend is towards the industry being dominated by a few large corporations operating on a national level, with some corporations even operating on a European or global scale. This process, which could significantly impact on the supplier-retailer relationships, is examined in this study using in-depth interviews with participants from the fresh produce supply chain. Amongst the findings are the following: Supply chain advancements including backhauling and factory gate pricing are causing some controversy because suppliers feel that these initiatives do not benefit their relationships with retailers. There is room for supplier-retailer relationship improvement in areas such as trust, co-operation, and collaboration. Retailers, who have significant supply chain power, are starting to acknowledge the importance of suppliers in the gaining of gaining retail market share. Lastly, the intense process of supplychain rationalisation that we have seen in recent years appears to be leveling out in UK fresh produce supply, such that there is less anticipated further rationalisation. The study outlines a series of recommendations for how suppliers (retailers) can improve their relationships with retailers (suppliers).
\end{abstract}

Key words: supplier-retailer relationships, marketing practice, purchasing practice, fresh produce industry. 


\section{Introduction}

We report on supplier-retailer relationships in the UK fresh produce supply chain. Over the past two decades, the literature has increasingly moved to consider collaborative relationship management and procurement practices (for major examinations, see for example Christopher, 1992; Gadde and Håkansson, 2001; Gattorna and Walters, 1996; Gemünden, Ritter, and Walter, 1997; Harrison, 1993; Saunders, 1994) and away from transactional exchange. Table 1 summarizes the differences between the two approaches. In particular, we look at the changes that have recently happened in the UK fresh produce supply chain and what the impact, if any, has been on supplier-retailer relationships.

\{Insert Table 1 around here\}

The chain, which includes fruit, vegetables, and salads (that are not tinned, frozen, or preserved and that have been harvested recently), has undergone numerous changes in the last decade, with retailers becoming increasingly powerful. For example, more than half of all UK fresh produce was sold through greengrocers in 1990 (Anonymous, 2000a), but by 2000 the retailer multiples' share stood at some 83 per cent of sales by value (Anonymous, 2000b). The implementation of modern business practices including Efficient Consumer Response (ECR), Category Management (CM), and Just-in-Time (JIT) management has helped improve efficiency in the UK fresh produce supply chain. This has allowed the chain to break out of the commodity trap and take the fresh produce category out of the trading environment (Fearne and Hughes, 2000: p. 120) by means of innovation and value creation (White, 2000). The overall trend is towards the UK fresh produce industry being dominated by a few large corporations operating on a national level, with some corporations even operating on a European or global scale. This process could have a deep impact on the relationships between suppliers and retailers. The research objective of our article is therefore to examine supplierretailer relationships in a supply chain that has and still is undergoing changes.

We organize the paper around the following topics. Firstly, we give a brief overview of the developments in the UK food supply chain. We then consider the developments in the fresh produce chain, particularly some of the practices that the industry has put in place over the last decade or so, as well as the effects that these changes have had. Management developments include logistical initiatives (just-in-time, central versus regional distribution, 
and third and fourth party logistic provision) and IT technology developments (bar code, electronic point of sales, electronic data interchange, continuous replenishment, and electronic commerce). Following that, we examine a number of players in the UK fresh produce supply chain. To that end, we carried out in-depth interviews with two suppliers, two retailers, and one haulier. Our main conclusions are as follows. Advancements in the UK fresh produce industry, particularly backhauling and factory gate pricing, have recently caused some controversy with suppliers feeling that these initiatives are not benefiting their relationships with retailers. Backhauling is the method of moving goods through a supply chain by fully utilising transport during its downtime (IGD, 2002a). Retailers' lorries will collect from suppliers on their return journeys and bring the goods to consolidation centers thus reducing transport costs and boosting efficiency considerably (Hunt, 2002). Suppliers will be expected to quote factory gate prices, i.e. product costs excluding primary distribution costs and hence lose control over price setting in the logistics function. Also, although relationships in the industry are good in some areas there is still room for improvement with regards to trust, cooperation, and collaboration. Retailers continue to have significant supply chain power compared to suppliers, but they are starting to acknowledge the importance of suppliers in gaining retail market share for fresh produce. Lastly, the threat of further supply chain rationalisation is now minimal thereby showing that remaining suppliers and retailers generally are working together to achieve more sales. Throughout the paper we draw on examples from the fresh produce supply chain that illustrate the relevance of our research findings in terms of managerial practice. Lastly, we point to some avenues for future research.

\section{Developments in the Food Supply Chain}

Food retailers command an increasingly higher volume of sales compared to food manufacturers and commodity suppliers thereby shifting the power within food marketing channels (Bourlakis, 2001; Fiddis, 1997). Retailer organisations have reaped the reward of market concentration; with, for example, Tesco taking a quarter of the value of UK grocery sales alone (IGD, 2004a; Tesco, 2004). The latest evidence suggests that not only will retailer buyer power continue to concentrate in the hands of the major players, further consolidation in the sector will take place both within and beyond the home market, with Tesco now a significant international player (IGD, 2004a; Tesco, 2004). Most recently, the takeover of one of the largest UK food retailers, Safeway by Wm. Morrison, has resulted in four major 
supermarket chains accounting for three-quarters of retail grocery sales (IGD, 2004a). This is evident from Table 2.

\{Insert Table 2 around here $\}$

Over the last twenty years the UK food industry has experienced concentration in most parts of the supply chain initiated by powerful multiple retail buyers (Collins and Burt, 1999; Galizzi and Venturini, 1996; Howe, 1998; Robson and Rawnsley, 2001). Acquisitions, mergers and internal restructuring have transformed the competitive environment, driven by a complex mix of technological, socio-economic and political changes (Traill and Pitts, 1998). Such developments are not restricted to the UK though, as Cook and Davies (2000) and Hobbs and Young (2000) report on similar trends being witnessed in the United States. The issue of retailer led concentration and corresponding detrimental impact on suppliers has also been identified in a European Union context (Hughes, 1994; Caprice, 2004). In the mature economies of Western Europe for example, the pattern of concentration in retailing is very similar to that of the UK, with the national market share for food of the three largest retailers in almost all of the Western European countries, even by the mid-1990's, in excess of 50 per cent of sales (Hanf and Hanf, 2004; IGD 2004b). The knock-on effect has been a similar pattern of concentration in the supply of food in Western Europe and in a wider European and global context. There is no reason, therefore, to suppose that conditions and findings in this study are not readily transferable to at least a Western European context.

From the 1980s, faced with disorderly supply deliveries from food manufacturers, UK retailers saw ownership of independent regional warehouses/distribution centres and transportation fleets as the solution to inefficiency and disruption, in order to secure timely supply deliveries. Later, however, food retailers opted to outsource the logistics function, when this was possible, to single firms that offer all necessary value-added services in addition to the logistics function (e.g. Browne and Allen, 1999; Dawson and Shaw, 1990; Fernie, 1998).

A further development has been a change from market transactions to market relationships, networks, and interactions (Axelsson and Wynstra, 2002; Bourlakis, 1998; Bowersox et al., 1992: Coviello, Brodie, Danaher, and Johnston, 2002; Gummesson, 1999; Hughes, 1994). Different factors have contributed to that development: the introduction of ECR in the early 
1990s, the internationalization of logistics firms, and the facilitating role information technology systems (Bourlakis, 2001; Kotzab, 2001). From the retailer perspective (and largely initiated by them) has been the development of Category Management (CM) as a key managerial tool. O'Keefe and Fearne (2002), for example, contend that their analysis of the application of category leadership in the fresh produce industry by UK retailer Waitrose shows that it is possible to successfully apply an integrated network-based relationship approach to what is considered to be a commodity sector. CM (where a preferred supply takes greater responsibility for the entire supply chain of a given product category) has become universally applied by retailers. The premise is that CM facilitates greater levels of collaboration in vertical supply channels and underpins relationship development (Barnes et al., 1995). This occurs where a single (lead) supplier organizes the supply (from all the suppliers) of a given product category to the retailer. However, such initiatives are seen by some to be simply moving risk and cost onto the supplier and away from the retailer (Allen, 2001). Interestingly, it has been suggested that suppliers who are not willing to engage in this system could set up alternative food supply chains (Hughes, 2000; Younger, 1998). This is an argument put forward in Dapiran and Hogarth-Scott (2003) who contend that the development of CM has not necessarily increased cooperation in supply chains and can be used by retailers to reinforce power and control.

\section{Developments in the UK Fresh Produce Supply Chain}

The UK fresh produce industry is characterized by over-supply, a commodity orientation, and stagnant annual growth (Fearne and Hughes, 2000). Retailers are driven by the need to reduce environmental uncertainty and risk (Hogarth-Scott, 1999), to improve supply chain integrity, to provide greater consistency in the quality of fresh produce, and to reduce costs through economies of scale. Additionally, they are looking for fewer and larger suppliers who can work with them in partnership (Bedford, 2000; Fearne and Hughes, 2000; Hingley, 2001; White, 2000). Hughes (1996), for example, states that retailers will continue to reduce the number of food suppliers, and this is in agreement with the general business trend towards industrial buyers rationalising their vendor relationships to a reasonable few (Dorsch, Swanson, and Kelly, 1998). This approach delivers considerable advantages for retailers, in that they can influence entire food channels for given products through singular dyadic interfaces with nominated channel leading intermediaries. Reducing the number of points of contact for supply not only derives benefits in terms of transaction cost savings, but also 
relational benefits in dealing with fewer but closer 'partner' suppliers. This has resulted in an overriding trend towards supply chain concentration of a market determined by the standards of large-scale retailers and manufacturers (Bourlakis and Weightman, 2004).

Such partnerships facilitate the stringent quality assurance and traceability programs imposed, whilst at the same time develop innovative ways of adding genuine value to the basic commodity in its movement from farm to consumer (Fearne and Hughes, 2000; Hughes, 2000). This has resulted in an overriding trend towards supply chain concentration, a process that could have a possible deep impact on the relationships, networks, and interactions between sellers and buyers, which makes the sector interesting.

In addition, UK supermarkets receive a considerable amount of criticism with regard to fair dealings with suppliers (see, for example, Howe, 1998). A report published by the Competition Commission (2000) on competitiveness and supply chain management by UK retailers highlights shortcomings in the treatment of suppliers to supermarkets. As a result, a code of practice has been drawn up by the Director General of Fair Trading in the UK to which most leading UK food retailers have agreed to comply. The code governs relations between major supermarkets and their suppliers and puts in place measures to remedy problems identified by the Competition Commission relating to the provision of independent dispute resolution; thus seeking to provide suppliers with greater certainty and security (Department of Trade and Industry, 2001). However, the code has not been welcomed in all quarters with public criticism from suppliers in the UK. Against this background of apparent unrest over supplier-retailer relationships it is of interest to identify experiences from those engaged in close-partnering relationships.

\section{Study Objectives in the Light of Previous Literature and Concepts}

This study brings into context an important industrial sector and set of business relationships that aptly illustrates and questions current thinking on business relationships and channel management, drawing on recent literature on Relationship Marketing (RM) and Supply Channel Relationships (SCR). Pertinent to this, specific management tools are investigated, for example that of Category Management (CM). Specific objectives with regard to these and further applied conceptual issues are as follows as the analysis and understanding of: 
- advancements in the UK fresh produce industry: technology, category management, backhauling, and factory gate pricing;

- recent changes in UK fresh produce supplier-retailer relationships: contact, collaboration, trust, power, fresh produce buyers, partnerships, and relationships; and

- future outlook for the UK fresh produce industry: rationalisation.

\section{Research Methodology}

It was decided to approach the questions using qualitative methods for collecting data. If fresh produce supply chain relationships are to be studied in depth it was believed that the most appropriate methods were those that emphasize detail, depth, and insight, as well as understanding and explanation (Patton, 1987; Sayre, 2001). In this research we used semistructured, personal interviews that allowed access to respondents' thoughts, opinions, attitudes, and motivational ideas. This is an approach that has been employed in similar research including Hingley (2001) and Lindgreen and Beverland (2004), amongst others. Since cases were selected for their ability to contribute new insights, as well as in the expectation that these insights would be replicated (Perry, 1998). Both theoretical breadth and category saturation was obtained.

We interviewed a number of organizations as part of our research (Table 3). A sample of suppliers with the desired characteristics was first located. Suppliers were selected for reasons of being typical examples of organizations, in this case fresh produce category management supply chain members (Miles and Huberman, 1994; Patton, 1987). Utilising a snowball approach (Patton, 1987) information was obtained on retailers with whom the suppliers had dealt with, and contact with these suppliers was established, by means of a letter with a follow-up telephone call two weeks later to monitor progress. All the interview respondents asked that they be kept anonymous in the research. First, with regards to suppliers to food retailers one large fruit supplier and one large vegetable supplier were selected; both players had been involved in vertical supply chains relationships. The interviews with the suppliers helped to give a general idea of suppliers' thoughts and visions, as well as views on partnerships with retailers. It was also possible to identify differences between two different supply chains (fruits versus vegetables). Then a large and a small multiple retailer were asked to participate in the research. The objectives of this set of interviews were to gain insights into retailers' attitudes towards their partnerships with suppliers and the future outlook of these 
partnerships. Knowledge was also gained on the influence of retailer size on the partnership with suppliers. Lastly, a large haulage company participated in the research. This company dealt regularly with suppliers and retailers in the fresh produce industry. The inclusion of the haulage company resulted in information on both back hauling and factory gate pricing. For additional information on the designing of the research we refer to Kinnear and Taylor (1996).

\{Insert Table 3 around here

The above organizations selected for depth interview provide suitable validity to the findings, specifically the two retail chains combined represent over one-third of UK food sales and represent both ends of the top 10 multiple chain food retailing organizations. Suppliers' are as identified above, typical of category lead businesses serving this sector. Further the haulage company is representative of relatively small number of dedicated specialist haulage businesses that focus on serving the needs of the fresh produce supplier-retailer relationship. All managers interviewed are at a senior decision making level. The retail managers, for example, represent buying and extended duties involved in their given category, and hence the study could be easily reproduced for further categories and in other top 10 or overseas retailer organizations in that the category based structure is commonplace (at the very least in Western countries).

Interview questions were standardized around a number of topics (Dibb et al., 1997). We refer to Tables 4 through 6 that contain both the topics for discussion and the text evidence from the interviews. Questions were kept deliberately broad to allow interviewees as much freedom in their answers as possible (Glaser and Strauss, 1967). The findings are taken from the words of the respondents themselves thereby aiding the aim of the research, whilst gaining much more information than would have been available from alternative research methods (Corbin and Strauss, 1998). All interviews were first taped to increase accuracy of data presentation (Patton, 1987) and later transcribed to allow for a detailed analysis. Eisenhardt's (1989) two-stage method of within-case and cross-case analysis guided the analysis of interview data. Within-case analysis involved writing up a summary of each individual case in order to identify important case level phenomena. Following this process, a coding scheme was developed to assist with the cross-case analysis (Patton, 1987; Strauss and Corbin, 1998) that involved searches for cross-case patterns (Miles and Huberman 1994). 
With qualitative data being notoriously difficult to analyze (Patton, 1987) the authors' findings were cross-checked by an anonymous outsider, who had experience in analyzing indepth interviews, to help achieve reliability. The case studies and interpretive reports were returned to the respondents for their comments, a step that helped further enhance the validity of the research method (Perry, 1998). To further help improve the quality of the analysis, secondary data were sought to triangulate the cases (Glaser and Strauss, 1967; Strauss and Corbin, 1998; Yin, 1994).

Although the case study may take a variety of forms (Yin, 1994) its essential characteristic is the inclusion of explicit presentations of the key evidence that was used to draw the conclusions. This, however, often results in the case study method becoming discursive, and readers often find the lengthy description of the findings exhausting. For the purposes of this study it was, therefore, decided to make use of the following reporting style: The main text discusses the findings and brings some text evidence to support the claims and towards the end of the article additional text evidence is found for each of the interview respondents. The literature review, as well as the previously mentioned coding scheme also helped in reporting the findings that are grouped under the three major objectives, each with a number of subheadings (identified above). Lastly, the discussion section considers the findings and, at the same time, brings in references to the relevant literature.

\section{Discussion of Findings}

\section{Advancements in the UK Fresh Produce Industry}

The following advancements are discussed: technology, category management, backhauling, and factory gate pricing.

\section{Technology}

Over the past decade, information technology has evolved quickly in the UK fresh produce industry including electronic data interchange and the Internet, amongst other technological initiatives. It has been suggested in the literature that the nature of fresh produce necessitates a high level of relational exchange, facilitated by technology. This is echoed in the following statement: 
"We are now involved as a company on so many different levels, with good communication between the retail buyer and account manager [as being] essential. We use E-mail a lot, with technology particularly useful in helping our planning with the retailer [and] aiding our communication and technical issues greatly." (Supplier Y)

Although it was generally felt that electronic data interchange facilitated business processes when sending orders, invoicing delivery notes, and interpreting label data, the cost of electronic data interchange proved a problem for suppliers:

"Technology can be expensive and unnecessary in certain applications. Tesco, for example, wanted us to pay $£ 5,000$ to $£ 10,000$ for the privilege of using TIE [Tesco Information Exchange], where the information we had access to was really not worth what they wanted us to pay for it." (Supplier X)

Produce needs to be replenished regularly to keep shelf space full with fresh produce (Fearne and O'Keefe, 2002), and the use of information technology is helping retailers, suppliers, and hauliers in this matter when they discuss issues such as stock levels, costings, and product forecasts:

"Good data exchange is vital in helping us manage the day-to-day volumes successfully, which can incidentally be very volatile." (Retailer X) Contact between suppliers and retailers, though, is still very much based on personal communication including face-to-face meetings. This is evident from the following statement:

"We have a common goal: getting the product onto the supermarket shelf, in the right condition, at the right price. All our focus is on meeting the consumers' demands." (Supplier X)

\section{Category management}

The introduction of CM was recognised by all respondents who agreed with Hogarth-Scott (1999) that good supplier-retailer working relationships are critical to CM even though one supplier company had never called themselves category managers:

"We consider the multiples and ourselves to be conduits, from the growers to the consumer[s], where ultimate consumer satisfaction is the goal." (Supplier X) 
Opinion on the long-term effect of CM differed, as Supplier Y, Retailer Y, and Haulier X believed that there would be further rationalisation of the fresh produce supply base thereby agreeing with Fearne and Hughes (2000), whilst Supplier X and Retailer X suggested that in time suppliers would become fewer in number, but more significant in given product categories (cif: Broadfoot, 2002; Hingley, 2001):

"We are now dealing with the best suppliers so there is not a lot more consolidation to go on. With there being fewer suppliers the ones that supply us are tending to supply us with more fresh produce over time." (Retailer X)

Respondents agreed with Christopher and Jüttner (2000) in that retailers choose suppliers on the level of commitment they demonstrate, and on the quality and price of products that they offer:

"We tend to work with larger suppliers who are successful and efficient. We also like to see investment from our suppliers." (Retailer X)

The fact that suppliers have not enthusiastically embraced CM and also have little trust towards retailers is supported by Bevilacqua and Petroni (2002), who argue that the larger company usually streamlines the number of suppliers to gain competitive advantage, but upsets other suppliers. This is echoed in the following statement:

"Asda, for example, are becoming more inclined to deal with fewer suppliers, and using one consolidator for certain fresh produce, which suppliers must go through. Naturally this gives great gains to the category captain, but not necessarily the other fresh produce suppliers." (Supplier Y)

Indeed, the respondents worried about the future possible influence of Asda in the UK fresh produce market. For example, Supplier X mentioned that Asda (subsidiary to the giant retailing global leader, Wal-Mart) are presently taking low-quality fresh produce at low prices thereby causing other retailers to demand higher quality fresh produce at nearly the same prices as Asda (in order to still be able to compete). This puts increasing pressure on suppliers to deliver fresh produce:

"Asda have reduced their supplier base in recent years considerably. I think it is fair to say that a lot of their suppliers at this moment in time are struggling to meet their demands, showing flaws in the category management process." (Retailer X) 


\section{Backhauling and factory gate pricing}

In agreement with previous findings, backhauling has increased in use over time with Asda, for example, increasing its use of backhauling with more than 100 per cent from 1998 to 2001; in a similar way other major retailers like Safeway and Tesco have increased their use of the system (Finegan, 2002).

There are mixed feelings towards backhauling and factory gate pricing. Some of the respondents agreed with Slater (2002) that the initiatives help increase volumes in the fresh produce supply chain and, in support of McAllister (2003), are now trying to work closer with retailers to help the process work. UK food retailer Waitrose's head of buying, Angela Megson, has stated in an interview that: Waitrose was exploring opportunities to initiate factory gate pricing, but would consult suppliers, thereby helping to highlight that certain retailers believe that it is important to maintain good relationships with suppliers when implementing new ideas. Retailer Y concurs with this as is evident from the following statement:

"We have a number of projects going on to do with factory gate pricing, but they are quite low key. We tend to consult suppliers first. Some of our suppliers have been with us decades and are important to us." (Retailer Y)

Still, both backhauling and factory gate pricing are of key concerns to suppliers who, like Rowai (2002), generally feel it will only benefit the retailers in the long run by allowing them to cut their own costs, but forgetting about the effect on supply chain partners, with one responding:

"Our vehicle fleet is now moving from A to B, at the lowest rates possible. All that saved money is going straight into the multiples' pockets. As a primary haulier, it is really borderline whether it is worth hauling altogether. We regularly question it, and I know of a lot of people that are currently thinking about disbanding their fleets." (Supplier Y)

Supplier X elaborated on the effects of backhauling and factory gate pricing: Contrarily to Finegan (2002) who suggest that the two initiatives will lead to great supply chain savings, this supplier argued that costings will go up and, further, that local haulage companies will also be losers in the factory gate pricing initiative, with his company committed to starting its own haulage fleet in order to maximise savings: 
"Our haulier wanted to increase our rates by 12 per cent so that the supermarket can take over the invoicing from ourselves, which means an additional costing of $£ 250,000$ to my company, and I cannot see any logical reason why this should happen. The retailers' motto is: 'better, simpler, cheaper' and it is none of the three. The result of this is that our haulier will stop working for us shortly, and we have put in place distribution for ourselves." (Supplier X)

This was acknowledged by Haulier $\mathrm{X}$ who had been anticipating these initiatives and stated:

"Backhauling and factory gate pricing are clearly about volume and critical mass.

We work with the retailers to try and help the process work and become involved at all levels." (Haulier X)

Indeed, there was an apparent agreement with suppliers and the haulage company that the advent of backhauling and factory gate pricing will decrease the suppliers' control over product distribution, yet further threatening supplier-retailer relationships (cif: IGD, 2003). However, ultimately the retailers are in the driving seat in the UK food supply chain with respect to backhauling and factory gate pricing; and as Sainsburys senior manager Richard Dickson states, "engagement in this process is not optional" (Hunt, 2002: p. 39).

\section{Recent Changes in UK Fresh Produce Supplier-Retailer Relationships}

The following changes will be discussed: contact, collaboration, trust, power, fresh produce buyers, and partnerships and relationships.

\section{Contact}

There has been a higher level of interaction between fresh produce suppliers and retailers in recent years in order to deal with daily issues (White, 2000). This was confirmed by all respondents, with Supplier Y having noticed a definite difference:

"There is now daily contact with retailers at all levels. It has really changed over the last two years. If I go back four or five years, it was generally the account manager who was talking to the multiples' buyer once or twice a week. That has changed, and you have now got the multiple buyer talking to the account manager, the technical manager talking to the multiple's technical people and so on. Contact is much more frequent."(Supplier Y) 
Respondents believe that good communication between suppliers and retailers is important, with it resulting in a more co-operative relationship (cif: Harris, Swatman, and Kurnai,1999) and an ability to respond rapidly to consumers' changing demands. It is also important if good quality produce is to be offered to consumers (cif: Jenkinson, 2002). However, Retailer Y highlighted Watson's (2002) view that retailers allow a lot of information to be passed back and forth to suppliers rather than work with them:

"We discuss forthcoming weather, the general market, [and] EU markets. We talk about a lot of things, but there are quite strict rules on what we can discuss with suppliers." (Retailer Y)

With regard to the haulier's contact with suppliers, contact has changed in recent years, with no contact between the haulier and suppliers regarding commercial or financial information.

\section{Collaboration}

Despite the fact that collaboration has been suggested as paramount to business growth (cif: Hollensen, 2003) collaboration apparently does not occur often enough in the industry:

"I feel that there is co-operation with all our suppliers, but not always collaboration. Those we feel that we collaborate with more we will reward in terms of volume." (Retailer Y)

Two different reasons for why collaboration does not happen have been suggested in the literature. One reason should be the lack of trust and commitment between suppliers and retailers (cif: Hogarth-Scott, 1999), while another should be that a business partner will always withhold information as a means of achieving his potentially goals that are not necessarily mutual to his partner.

\section{Trust}

The success of supply chain relationships is to a large extent determined by the level of trust, which aids co-operation in supply chain processes (Axtell et al., 2002; Hingley and Lindgreen, 2002; Hogarth-Scott, 1999). There appeared to be an underlying lack of trust in the industry, which was voiced by a retailer in the following way:

"Building trust and getting better visibility in the fresh produce supply chain is something that needs to be worked at. Trust always needs to be there between supplier and retailer." (Retailer Y)

One explanation could be that some retailers are not helping the process by being open to their suppliers to which problem there are two options (cif: Axtell et al., 2002): 
"There is still a feeling with certain retailers that it is us and them, and there is no trust. If you do not have a trust with your supply base, stop and pull away, or try and work out the problems." (Supplier Y)

\section{Power}

The research confirmed Hingley's (2001) suggestion that fresh produce suppliers, as well as the haulier perceive an imbalance of power, with the majority of control falling in the hands of the retailers. This is echoed in the following two statements:

"We feel that we could do a better job in the fresh produce industry if the retailers let us have more of a free reign." (Supplier X)

"If the supermarkets did not have as much power - and so the general consensus of opinion coming from the supermarkets was not so one sided - things would be better." (Supplier Y)

Power imbalance can be detrimental to sustaining a business relationship (e.g., Gummesson, 1999) so it becomes key that a business partner does not feel completely powerless. One respondent, for example, felt that they needed to demonstrate some degree of power redress:

"If we feel that we have a difference of opinion with the retailer we will not be pushed into a corner. We will stand our ground."(Supplier X)

The fact remains, though, that the multiples control nearly two-thirds of grocery sales and in turn expect increasingly exacting commitment from suppliers, emphasising how power still influences the fresh produce market. Tesco alone controls 30 per cent of the retail fresh produce market (Leighton, 2003). Consequently there is a situation of power imbalance in UK fresh produce supply and the significant issue for actors in the future will not be in resisting this, but in learning ways of managing the imbalance.

\section{Fresh produce buyers}

Fearne and O'Keefe's (2002) proposition - the use of CM in the fresh produce industry has allowed retailers to work more closely with suppliers to reduce costs, and grow this category was accepted by the respondents who expressed concern, though, about the length of time retailers have kept buyers in post, in the past:

"We used to only have a buyer for probably no more than two years maximum.

They would have one season under their belt, just learnt what the situation was, and then by the second season, they are gone and you have to start all over again. 
This was a big frustration from 1995 to 2000 because you could not actually build a relationship with the retailers." (Supplier Y)

This belief - that buyers are influential in relationship building confirms previous research by Axtell et al. (2002) and White (2000) - was elaborated on by Retailer Y:

"Keeping buyers is important to relationships. It does not help the job when retailers move buyers on. It would frustrate me, as a buyer, if I got moved on after just one year, as I would only just have started to get to know some of our suppliers." (Retailer Y)

Recently, there has been a realisation among retailers that timing is important to relationship development, and this has resulted in changes to retailers' buyer policy:

"Just recently, the changing of buyers has started to slow down, which has improved our relationship with them. Some retailers do not change their buyers for years. Waitrose, for example, has had a buyer, we deal with, for six years. Relationships with them are thus very good." (Supplier Y)

\section{Partnerships}

Fearne and Hughes (2000) posited that recently retailers have been keen to establish single supply or preferred supplier partnerships with selected fresh produce suppliers in a move to squeeze costs out of the supply chain. This research highlighted the fact that interestingly there is some uncertainty with what the term partnership exactly means:

"I would first of all want to know what the word 'partnership' actually stands for." (Supplier X)

Although the term may not be easily understood, partnerships are still of major concern to both suppliers and retailers. On the one hand, both of the interviewed suppliers agreed that partnerships offer the most to the more powerful business partner (see also Christopher and Jüttner, 2000; Lavelle and Wilson, 1996), which is in contrast to those researchers who have argued, for example, that both partners are sharing mutually achievable goals (e.g., Hollensen, 2003):

"I used to think partnerships were a good thing, but not anymore. The multiples are currently taking the word partnership and want an open book policy. They are picking bits of information they want from us and using it to reduce the price to the grower. They are just taking what they want." (Supplier Y) 
The retailers and the haulage company, on the other hand, favoured the arguments of Hingley (2001) and White (2000) that partnerships results in retailers becoming far less aggressive to suppliers and more inclined to share joint benefits. Thus Haulier X stated that more volume could be achieved by means of a partnership strategy, and the retailers argued that they could develop stronger relationships with their suppliers through partnerships:

"Partnerships are key to us in terms of quality, service, and price to our customers.

We cannot do that without the strengths and excellence of our supply base.

Without that we would struggle." (Retailer X)

"The benefits of a partnership are immense. It gives suppliers confidence and security and allows us to develop stronger links with our supply base, developing our relationship, whilst also driving up fresh produce sales." (Retailer Y)

\section{Relationships}

All of the respondents argued, along the lines of Grbac and Martin (2003) that strong relationships impact on a firm's performance. They also recognised the crucial importance of supplier-retailer relationships in helping retailers with product freshness, quality, and continuity, thereby confirming White's (2000) and Dyer's (2000) research. One case in point is Retailer X who felt the success of the company and the products and services they offer are linked to the relationship they are in:

"The key suppliers we work with, we are in good relationships with. They work very well and provide us with what we require. Our relationships with them are about discussions, discussing prices and volumes." (Retailer X)

Some retailers are loath to develop relationships with suppliers who also work for rival retailers (cif: Fearne and O'Keefe, 2002):

"There are difficulties in relationships such as suppliers supplying a number of retailers. We will not deal as keenly with them, as we would suppliers dedicated to us and who are trying to make us the key winner." (Retailer X)

Difficulties in a relationship could potentially result in vulnerability (cif: Svensson, 2002):

"We are having a hard time at the moment, with the demands from the supermarkets having increased immensely, and it is not actually showing on the bottom line. We are getting paid less, yet doing a lot more work. That is no relationship." (Supplier Y) 
Despite such challenges all respondents believed that the relationships have improved over the past two years thereby highlighting that the Competition Commission (2000) report may have had an influence on fresh produce supply chain relationships, though Fearne and Hughes (2000) posit that retailers will operate with a reduced supplier base, but increased dedication to that supply base. However, Supplier X argued that it was important for retailers to have a balance of suppliers, some cheaper than others, if retailers want a lower price on the shelf to be available. This is illustrated by some aggressive fresh produce pricing in recent times in the UK, most notably by Asda.

Lastly, respondents suggested a range of approaches to improving relationships including the following ones:

- make all activities part of a partnership;

- involve supply chain partners early on;

- increase co-operation, collaboration, and trust between supply chain partners;

- give suppliers more control; and

- improve long-term planning and investment;

\section{Future Outlook for the UK Fresh Produce Industry}

\section{Rationalisation}

Respondents all concur with Broadfoot's (2002) who suggested that the fresh produce supplier base could, over time, be reduced by as much as 75 per cent. Rationalisation, which partly has made this possible, has now slowed down thereby creating opportunities. Suppliers, therefore, generally believe that rationalisation could benefit them by delivering business growth with from fewer and bigger suppliers dealing with fewer and bigger retailers (cif: Hingley, 2001):

"Our business grew with one retailer by 10 per cent when they expected five per cent last year, highlighting that we must be satisfying them and getting quality and price right." (Supplier X)

There was disagreement on whether or not a reduction in suppliers will result in more suppliers joining together as larger supplier co-operatives (cif: Gibbs and Shaw, 2000; White, 2000) in order to create a countervailing force in the market place. This is, for example, 
disregarded by Supplier X, as is evident from the following statement, which emphasizes the independent nature of UK suppliers:

"We do not talk to competitors in terms of pricing. We are fiercely independent and, without being conceited or being arrogant, we generally see ourselves as trying to do the best job, with people continually learning from us." (Supplier X)

\section{Consumption}

The research supports the reviewed literature in that fresh produce consumption is increasing, especially in the area of fruit (IGD, 2002):

"I work with fruit and I think the potential for it is immense. The future is bright. I

do not think it is rosy, but if I was a good supplier I would be reasonably

optimistic about the future." (Retailer Y)

All respondents acknowledged that product innovation and quality are key determinants in ongoing fresh produce sales (cif: Fearne and Hughes, 2000).

\section{Conclusions}

Our research suggests that advancements in the UK fresh produce industry have caused some controversy in recent years, particularly with regards to backhauling and factory gate pricing where suppliers generally felt that these initiatives are not benefiting their relationships with retailers. We also find that, in some areas, relationships are improving in the industry, though issues such as trust, co-operation, and collaboration should be addressed if further improvements are to occur. Retailers continue to have significant supply chain power compared to suppliers although they are beginning to acknowledge how important suppliers are to gaining market share for fresh produce. Lastly, fresh produce sales are still buoyant demonstrating the change in consumer eating habits and lifestyles in recent years. The threat of further rationalisation is now minimal thereby showing that suppliers and retailers generally are working together to achieve more fresh produce sales.

\section{Managerial Recommendations}

In the light of developments in areas such as CM it is clear that in order to perpetuate successful and profitable relationships with their customers, the onus is on suppliers to provide competitively priced product and continual consistent quality of supply in order to 
retain their status with retailers, as category leaders. These suppliers must also show leadership in their category by being genuinely innovative. For such close, category-based relationships to work, both parties must engage in regular and close interaction. Retailers are the stronger party in the exchange relationship and they do place the burden of initiative on suppliers to meet their needs. Outputs (rewards) of relationships between power-size imbalanced parties are naturally imbalanced. However, this can still result in successful, workable (although not fully equitable), and ongoing relational exchange if this is conducted on the basis of regular two-way communication, joint problem solving and so forth. As a result there is a necessity for retailers to take the lead on this.

It is possible, therefore, to outline a number of recommendations for how suppliers (retailers) can improve their relationships with retailers (suppliers).

Suppliers should:

- continue to keep fresh produce quality high and price levels of fresh produce competitive, while working with retailers to achieve this;

- be innovative and provide retailers with unique fresh produce, as well as new marketing ideas;

- $\quad$ keep in regular contact with retailers and discuss problems; and

- invest in technology, where appropriate, and become as efficient as possible, showing a willingness to provide retailers with the best quality fresh produce achievable.

Retailers should:

- use the skills and product knowledge of suppliers to help out with difficulties in achieving certain targets;

- place importance on regular contact with suppliers, and make it verbally where possible;

- discuss any quality and price issues of fresh produce with suppliers, and work with them to find solutions to problems; and

- place importance on meaningful and equitable partnerships and reward suppliers who provide good quality fresh produce regularly. 


\section{Limitations to the Research}

It was described how, after a sample of suppliers had been located, information was obtained on retailers with whom the suppliers had dealt with and how contact with these suppliers was then established. Although this approach results in a sample that is less representative of the population than do other research methods (McNeill, 1990) the advantage is that it allows for identification of respondents who are likely to be willing to participate in the study. A series of interviews with additional suppliers and retailers should be set up to see if the research findings can be supported. Thought should be given into the sampling procedure. For example, cases should be included where it is believed that the findings will be in contrast to the ones in this research, or cases of supplier-retailer relationships that work well and relationships that work less well could be part of the research. Another example is the inclusion of international players in the research, as they could have a potential influence on the supply chain.

\section{Directions for Future Research}

Future research could examine issues of whether relationship marketing models are truly being applied in this sector. It appears that fresh produce vertical relationships are undergoing a step change. Powerful UK retail buying organizations applied collaborative relationshipbased constructs with respect to fresh produce suppliers; supply chains were shortened, supplier numbers rationalized and partner arrangements employed with dedicated and exclusive suppliers. This delivered some degree of ongoing relationship-based exchange in the sector. However, true partnership is difficult to achieve amongst unequals in vertical supply chains, where there must always be a lead partner. Fresh produce suppliers are broadly accepting this state of power imbalance (Hingley, 2001) just so long as a reasonable proportion of the relationship value accrues to them. But, it could be argued that vertical fresh produce (and other similar) food industry relationships between suppliers and retailers are entering another phase and retailers are using what have been previously declared are relationship-building tools as perhaps the opposite. Dapiran and Hogarth-Scott (2003), for example, contend that rather than building mutual relationships category management can be used by retailers to reinforce power-dependence over suppliers. Similarly, and as has been seen in this study, the introduction of backhauling and factory gate pricing has not been received well by suppliers. What in theory developed as an application of relationship 
marketing principles to this vertical channel has evolved and, some could say, regressed. Exchange has not reverted back to transactional dealings in fresh produce, there remains a reduced supply base model where key suppliers are more involved and regularly consulted in the business process. However, partnering and mutuality issues have not been fully realized. $\mathrm{CM}$ has brought to the fore the issue of power-dependence rather than mutuality. This does not, however, mean that imbalanced power relationships are not workable in vertical channels. Hence further research should focus on the nature and management of power in vertical channel relationships. This does not necessarily mean investigation into legality and fairness present in retailer-supplier relationships. This is more than adequately explored in Howe (1998) and Duffy et al. (2003) in reference to outcomes resulting from Competition Commission (2000). Quite clearly food industry suppliers can successfully operate in a power-imbalanced environment and this does question the relationships marketing premise of mutuality in collaborative exchange. It would be useful to comprehend, from the perspective of actors involved, the boundaries for and levels of acceptance in power-imbalanced vertical channel relationships.

\section{References}

Allen, S. (2001), "Changes in supply chain structure: the impact of expanding consumer choice", in Eastham, J. F., Sharples, L. and Ball, S. D. (2001), Food Supply Chain Management: Issues for the Hospitality and Retail Sectors, Butterworth-Heinemann, Oxford, pp. 314-323.

Axelsson, B. and Wynstra, F. (2002), Buying Business Services, John Wiley \& Sons, Chichester.

Axtell, C. M., Bennett, S., Clegg, C., Icasati-Johanson, B., and Riddalls, C. E. (2002), "Quantifying the effects of trust in supply chains during promotional periods", International Journal of Logistics, Vol. 5, No. 3, pp. 1-18.

Barnes, S., McGrath, M., and Pinnock, A. (1995), The Category Management Revolution, Institute of Grocery Distribution, Watford.

Bedford, L. (2000), Future Trends in the Fresh Produce Sector, Chipping Campden, Gloucestershire: Campden and Chorleywood Food Research Association, Wychavon District Council Adapt Food Quality Project, December, Report Number AG/55109/1. 
Bevilacqua, M. and Petroni, A. (2002), "From traditional purchasing to supplier management: a fuzzy approach to supplier selection", International Journal of Logistics, Vol. 5, No. 3, pp. 236-251.

Bourlakis, M. A. (2001), "Future issues in European supply chain management", in Eastham, J. F., Sharples, L. and Ball, S. D. (2001), Food Supply Chain Management: Issues for the Hospitality and Retail Sectors, Butterworth-Heinemann, Oxford, pp. 297-303.

Bourlakis, M. A., and Weightman, P. W. H. (2004), Introduction to the UK food supply chain. Blackwell Publishing Ltd.

Broadfoot, R. (2002), "British supermarkets focus on category management", Eurofruit Magazine, December-January, pp. 44-46.

Browne, M. and Allen, J. (1999), "Developments in Western European logistics strategies", in Walters, D. (Ed.), Global Logistics and Distribution Planning, Kogan Page, London, pp. 324-342.

Caprice, S. (2004), "The balance of power between manufacturers and retailers in accordance with the listings of products", in Proceedings of 88th Seminar, European Association of Agricultural Economics, 5-6 May, Paris, France.

Christopher, M. (1992), Logistics and Supply Chain Management, Pitman, London.

Christopher, M. and Jüttner, U. (2000), "Supply chain relationships: making the transition to closer integration", International Journal of Logistics, Vol. 3, No. 1, pp. 1-16.

Collins, A., and Burt, S. (1999), "Dependency in manufacturer-retailer relationships: the potential implications of retail internationalisation for indigenous food manufacturers", Journal of Marketing Management, Vol. 15, No. 1, pp. 673-693.

Competition Commission (2000) Supermarkets: A Report on the Supply of Groceries from Multiple Stores in the United Kingdom, Competition Commission, London.

Cook, R., and Davies, U. C. (2000), "The fresh fruit and vegetable value chain faces new forces for change", in Proceedings of the AAEA Pre-Conference Workshop on Policy Issues and the Changing Structure of the Food System. July, Tampa, Florida.

Corbin, J. and Strauss, A. (1998), Basics of Qualitative Research, Sage Publications, London.

Coviello, N. E., Brodie, R. J., Danaher, P. J., and Johnston, W. J. (2002), "How firms relate to their markets: an empirical examination of contemporary marketing practices", Journal of Marketing, Vol. 66, No. 3, pp. 33-46. 
Dapiran, G. P. and Hogarth-Scott, S. (2003), "Are co-operation and trust being confused with power? An analysis of food retailing in Australia and the UK", International Journal of Retail and Distribution Management, Vol. 31, No. 5, pp. 256-267.

Dawson, J. A. and Shaw, S. (1990), "The changing character of retailer-supplier relationships". In Fernie, J. (Ed.), Retail Distribution Management, Kogan Page, London, pp.

Department of Trade and Industry (2001), "Hewitt backs good behaviour code for supermarkets and suppliers", Department of Trade and Industry, press release, P/2001/606, 31 October.

Dibb, S., Ferrell, O. C., Pride, W. M., and Simkin, L. (1997), Marketing Concepts and Strategies, 3rd ed., Houghton Mifflin, Boston, Massachusetts.

Dorsch, M. J., Swanson, S. R., and Kelly, S. W. (1998), "The role of relationship quality in the stratification of vendors as perceived by customers", Academy of Marketing Science, Vol. 26, No. 2, pp. 128-142.

Duffy, R., Fearne A., and Hornibrook, S. (2003), "Measuring distributive justice and procedural justice: an exploratory investigation of the fairness of retailer-supplier relationships in the UK food industry", British Food Journal, Vol. 105, No. 10, pp. 682694.

Dyer, J. H. (2000), Collaborative Advantage: Winning through extended enterprise supplier networks. Oxford University Press, New York.

Eisenhardt, K. M. (1989) "Building theories from case study research", Academy of Management Review, Vol. 14, No. 4, pp. 532-550.

Eurofood, (2004), "Retail market shares", Eurofood, 25 March, p. 16.

Fearne, A. and Hughes, D. (2000), "Success factors in the fresh produce supply chain: insights from the UK", British Food Journal, Vol. 102, No.10, pp. 760-776.

Fearne, A. and O'Keefe, M. (2002), "From commodity marketing to category management", Supply Chain Management: An International Journal, Vol. 7, No. 5, pp. 296-301.

Fernie, J. (1998), "The internationalization of the retail supply chain". In Fernie, J. (Ed.), Retail Distribution Management, Kogan Page, London, pp. 47-66.

Fiddis, C. (1997), Manufacturer Retailer Relationships in the Food and Drink Industry: Strategies and Tactics in the Battle for Power, FT Retail and Consumer Publishing / Pearson Professional, London.

Finegan, N. (2002), Backhauling and Factory Gate Pricing: Evolution or Revolution? IGD Business Publications, Watford. 
Gadde, L.-E. and Håkansson, H. (2001), Supply Network Strategies, John Wiley \& Sons, Chichester.

Galizzi, G., and Venturini, L. (Eds.) (1996), Economics of Innovation: The Case of the Food Industry, Physica-Verlag, Heidelberg.

Gattorna, J. L. and Walters, D. W. (1996), Managing the Supply Chain, Macmillan, Basingstoke.

Gemünden, H. G., Ritter, T., and Walter, A. (1997), Relationships and Networks in International Markets, Pergamon, Oxford.

Gibbs, J. and Shaw, S. A. (2000), "International strategic alliance formation in the fresh produce industry", in Trienekens, J. H. and Zuurbier, P. J. P. (Eds.), Proceedings of the 4th International Conference on Chain Management in Agribusiness and the Food Industry, 25-26 May, Wageningen Agricultural University \& The Foundation for Agri-Chain Competence, Wageningen, pp. 237-243.

Glaser, B. G. and Strauss, A. L. (1967), The Discovery of Grounded Theory, Aldine de Gruyter, New York.

Grbac, B. and Martin, J. H. (2003), "Using supply chain management to leverage a firm's market orientation", Industrial Marketing Management, Vol. 32, No. 1, pp. 25-38.

Gummesson, E. (1999), Total Relationship Marketing: From the 4Ps-product, price, promotion, place - of traditional marketing management to the 30Rs - the thirty relationships - of the new marketing paradigm, Butterworth-Heinemann, Oxford.

Hanf, C.-H., and Hanf, J. H. (2004), "Internationalisation of food retail firms and its impact on food suppliers", in Proceedings of 88th Seminar, European Association of Agricultural Economics, 5-6 May, Paris, France.

Harris, J. K., Swatman, P. M. C., and Kurnai, S. (1999), "Efficient consumer response", Supply Chain Management: An International Journal, Vol. 4, No. 1, pp. 35-42.

Harrison, A. (1993), Just-in-Time Manufacturing in Perspective, Prentice Hall, London.

Hingley, M. (2001), "Relationship management in the supply chain", International Journal of Logistics Management, Vol. 12, No. 2, pp. 57-71.

Hingley, M. and Lindgreen, A. (2002), "Marketing of agricultural products: case findings", British Food Journal, Vol. 104, No. 10, pp. 806-827.

Hobbs, J. E. and Young, L. M. (2000), "Closer vertical co-ordination in agri-food supply chains: a conceptual framework and some preliminary evidence", Supply Chain Management, Vol. 5, No. 3, pp. 131-143. 
Hogarth-Scott, S. (1999), "Retailer-supplier partnerships: hostages to fortune or the way forward for the millenium", British Food Journal, Vol. 101, No. 9, pp. 668-682.

Hollensen, S. (2003), Marketing Management: A Relationship Approach, Pearson Education, London.

Howe, W.S. (1998), "Vertical market relations in the UK grocery trade: analysis and government policy", International Journal of Retail and Distribution Management, Vol. 26, No. 6, pp. 212-224.

Hughes, D. (1994), Breaking With Tradition: Building Partnerships \& Alliances in the European Food Industry, Wye College Press, Wye.

Hughes, D. (1996), "Reversing market trends: the challenge for the UK fresh fruit sector", British Food Journal Vol. 98, No. 9, pp.19-25.

Hughes, D. (2000), Challenges for the fresh produce industry in the twenty-first century, Food Project Fresh Produce Group, Wye College. Available from www.igd.com.

Hunt, J. (2002), "One step beyond - factory gate pricing", The Grocer, March, pp. 39-40. IGD (2002), Backhauling and Factory Gate Pricing, Institute of Grocery Distribution, Letchmore Heath.

IGD (2002), Food Consumption, Institute of Grocery Distribution, Letchmore Heath. IGD (2003), Retail Logistics - Benchmarking Supply Chains, Institute of Grocery

Distribution, Letchmore Heath.

IGD, (2004a), Grocery retailing: The market review, 2004. IGD Business Publications, Institute of Grocery Distribution, Watford.

IGD, (2004b), European grocery retailing, 2004. IGD Business Publications, Institute of Grocery Distribution, Watford.

Kinnear, T. C. and Taylor, J. R. (1996), Marketing Research, 5th ed., McGraw-Hill, London.

Kotzab, H. (2001), "European developments in efficient consumer response", in Eastham, J. F., Sharples, L. and Ball, S. D. (2001), Food Supply Chain Management: Issues for the Hospitality and Retail Sectors, Butterworth-Heinemann, Oxford, pp. 268-280.

Lavelle, D. and Wilson, N. (1996), An Evolution of Supply Chain Management and Perishable Products, Food Industry Discussion Paper No. 12, February.

Leighton, T. (2003), "Tesco steal", Fresh Produce Journal, 11 April, p. 1.

Lindgreen, A. and Beverland, M. (2004), "Relationship marketing: fad or panacea?" Journal of International Food \& Agribusiness Marketing, forthcoming in Vol. 15, No. 3.

McAlister, S. (2003), "Beyond the gate", The Grocer, 1 March, pp. 32-33. 
Miles, M. B. and Huberman, A. M. (1994), Qualitative Data analysis, 2nd ed., Sage Publications, Thousand Oaks, California.

O'Keefe, M. and Fearne, A. (2002), "From commodity marketing to category management: insights from the Waitrose category leadership programme in fresh produce", Supply Chain Management, Vol. 7, No. 5, pp. 296-301.

Patton, M. Q. (1987), How to Use Qualitative Methods in Evaluation, 2nd ed., Sage Publications, London.

Perry, C. (1998), "Processes of a case study methodology for postgraduate research in marketing", European Journal of Marketing, Vol. 32, No. 9/10, pp. 785-802.

Robson, I. and Rawnsley, V. (2001), "Co-operation or coercion? Supplier networks and relationships in the UK food industry", Supply Chain Management, Vol. 6, No. 1, pp. 3947.

Rowai, C. (2002), "Factory gate pricing", Distribution, April, p. 10.

Saunders, M. (1994), Strategic Purchasing and Supply Chain Management, Pitman, London.

Sayre, S. (2001), Qualitative Methods for Marketplace Research, Sage Publications, Thousand Oaks, California.

Slater, T. (2002), "Changing times", Checkout Fresh, July, pp. 9-10.

Strauss, A. and Corbin, J. (1992), Basics of Qualitative Research, Sage Publications, Newbury Park, Connecticut.

Svensson, G. (2002), "Vulnerability scenarios in marketing channels", Supply Chain Management: An International Journal, Vol. 7, No. 5, pp. 322-333.

Tesco, (2004), Financial highlights, Online http://www.tesco.com/corporateinfo. Accessed 2 August 2004].

Traill, B. and Pitts, E. (Eds.), (1998), Competitiveness in the Food Industry, Blackie A\&P, London.

van Weele, A. J. (2002), Purchasing and Supply Chain Management, 3rd ed., Thomsen Learning, London.

Watson, E. (2002), "Londis and co-ops ECR collaboration delivers", The Grocer, April 27.

White, H. M. F. (2000), "Buyer-supplier relationships in the UK fresh produce industry", British Food Journal, Vol. 102, No. 1, pp. 6-17.

Yin, R. K. (1994), Case Study Research: Design and Methods, 2nd ed., Sage Publications, Thousand Oaks, California. 
Table 1. Transactional-oriented versus relational-oriented purchasing behavior

\begin{tabular}{|c|c|}
\hline Transactional-oriented approach & Relational-oriented approach \\
\hline Many alternatives & One or few alternatives \\
\hline $\begin{array}{l}\text { Every deal is a new business, and no-one should } \\
\text { benefit from past performances }\end{array}$ & $\begin{array}{l}\text { A deal is part of a relationship, and the } \\
\text { relationship is part of a network context }\end{array}$ \\
\hline Exploit the potential of competition & Exploit the potential of co-operation \\
\hline $\begin{array}{l}\text { Short-term, arm's length distance, and avoid } \\
\text { coming too close }\end{array}$ & $\begin{array}{l}\text { Long-term with tough demands and joint } \\
\text { development }\end{array}$ \\
\hline $\begin{array}{l}\text { Renewal and effectiveness by change of partner, } \\
\text { and choose the most efficient supplier at any } \\
\text { time }\end{array}$ & $\begin{array}{l}\text { Renewal and effectiveness by collaboration and } \\
\text { team effects, and combine resources and } \\
\text { knowledge }\end{array}$ \\
\hline Buying products & Buying capabilities \\
\hline $\begin{array}{l}\rightarrow \text { Price-orientation, strong in achieving } \\
\text { favorable prices in well-specified products }\end{array}$ & $\begin{array}{l}\rightarrow \text { Cost- and value-orientation, strong in } \\
\text { achieving low total costs of supply and } \\
\text { developing new value }\end{array}$ \\
\hline
\end{tabular}

Source: Axelsson and Wynstra (2002: p. 214)

Table 2. Retail grocery market shares of the UK 'big-four'

\begin{tabular}{lll}
\hline & $\mathbf{2 0 0 4}$ & $\mathbf{2 0 0 3}$ \\
\hline Tesco & $28.1 \%$ & $26.7 \%$ \\
Asda & $16.2 \%$ & $16.5 \%$ \\
Sainsbury & $15.5 \%$ & $16.3 \%$ \\
Morrison/Safeway & $13.9 \%$ & $14.7 \%$ \\
\hline
\end{tabular}

Source: Adapted from Eurofood (2004) quoting TNS statistics 
Table 3. Organizations interviewed for the study

\begin{tabular}{lll}
\hline Firm type & Firm background & Position of interviewee \\
\hline Supplier X & Large fruit supplier & Senior manager \\
Supplier Y & Large vegetable supplier & Senior manager \\
Retailer X & Large multiple retailer (in & Category manager \\
& UK top 4) & \\
Retailer Y & Multiple retailer (in UK top & Category manager \\
& 10) & \\
Haulier & Large company specializing & Senior manager \\
& in fresh produce & \\
\hline
\end{tabular}




\section{Table 4a. In-depth Supplier X interview protocol, with some text evidence}

\section{Probing question}

How many years have you been involved as a supplier in the UK fresh produce industry? (Possible areas: year started, growth, multiples)

How would you describe the type of contact that you currently have with retailers? (Possible areas: daily, weekly, meetings, Internet, telephone)

What is discussed during this contact, and has technology such as Internet benefited this in any way? (Possible areas: production rates, problems, future stock requirements, exchange of ideas, transportation)

How would you describe your relationship with retailers? (Possible areas: positive, improving, collaborative)

What effect have the concepts of backhauling and factory gate pricing had on your business? (Possible areas: costing, pressure, relationships, haulage outlooks)

The concept of category management has seen a decline in fresh produce suppliers over time. Do you feel this trend will continue? (Possible areas: rationalization, favored suppliers, long-term and short-term effects)

What do you think are the benefits of a partnership between suppliers and retailers? (Possible areas: improved sales, better quality, improved relationship, mutuality)

\section{Text evidence}

"Thirty-one years in total, and about twenty-one years to the multiples."

"Depending on the retailer, contact can be up to six or seven times a day, on the 'phone, though the Internet is always looked at for extra input, with the managing director's individual contact with the retailers approximately twenty times a year."

"Technical issues mainly, with reference to the 24-hour traceability check. The focus is on verbal communication, though technology has allowed a wider range of data to become available. Stock control issues are also discussed, as are stock levels. Payments, price queries, and packaging design also come into the conversation."

"We have no set contract with retailers, with out business being based on getting a good return from our growers, concentrating on our customers' customers. Right from the start we have been interested in the end consumer. If we had a corner shop and customers coming into it, we would have to satisfy those customers. Repeat purchase is therefore very important to us. Our relationship with retailers can be cordial or sparky, depending on the situation. If we are in a situation, where we will not be pushed into a corner, we will stand our ground. We sometimes view our customers as high price and sometimes difficult to deal with. We have built the business over 15 years, from nothing to $£ 78$ million turnover, with an acceptable level of profit."

"Backhauling is looked after by a local haulier, who is a nominated haulier by a certain number of retailers in this area including Tesco and Safeway. I think we are two-to-three years ahead of the multiples in terms of cost savings on food miles. We are currently undergoing a situation with our haulier, for Tesco's factory gate pricing initiative, whereby our haulier want to increase our rates by $12 \%$, so then the supermarket can take over the invoicing from ourselves, which means a quarter of a million pounds additional costing, and we cannot see any logical reason why this should happen. The retailers' motto is 'better, simpler, cheaper' and it is none of the three. The result of this is that our haulier will stop working for us shortly as we have requested and we have put in place distribution for ourselves. We have been considering this anyway for the last two years, but issues of health and safety have had to be considered. We have storage facilities in Sheerness and Bristol and Newport opening, with the opportunities limitless in terms of what can be saved in food miles. We have one person at the moment based in New Zealand who is looking at different ways of getting our products to the multiples in the most cost-effective way."

"We have never called ourselves a category manager. We consider the multiples and ourselves to be conduits from the grower to the consumer. Marks and Spencer refer to us as category managers, which we share with another fruit supplier, but Tesco have never really embraced the concept of category management - we are instead category champions and get involved with promotional plans, packaging initiatives, and other different concepts."

"I would want to know what the partnership was first of all. We have a common goal, getting the product onto the supermarket shelf, in the right condition, at the right time, at the right price. All our focus is on the consumer. If we do a good job for the consumer, and a good job for the supermarket, then we will have a business. We have talked about open book pricing in the past, and it comes in cycles. There seems to be new initiatives that come along, usually originating from the USA. It is difficult to see where the benefits are in a partnership from our point of view. We are already considered good, and a company that others benchmark up to." 


\section{Table 4a. In-depth Supplier X interview protocol, with some text evidence, continued}

\section{Probing question}

Do you personally feel that you are working in a partnership with all the selected retailers? (Possible areas: recent schemes, move to certain suppliers, supplier attitudes and ideas)

If not, what are the problems that are currently arising? (Possible areas: lack of trust, cooperation, attitudes)

How do you feel your relationships can be improved with current retailers? (Possible areas: cooperation, collaboration, partnerships, improved customer satisfaction)

What are your feelings towards the future outlook for the UK fresh produce industry? (Possible areas: rationalization, efficient suppliers, commitment)

\section{Text evidence}

"We think we could do a better job if we were allowed to have more of a free reign, but there is a problem at the moment in the industry, whereby Asda are taking low quality at a low price because they want a lower margin, and other retailers are demanding higher quality at a higher margin, at the same price as Asda. To date, we have been successful in managing it, but it is going to get more and more difficult, as time goes on."

"Our relationship with Marks and Spencer is very strong. We also have a good relationship with Tesco. What I have just talked about affects them, as well as us. Retailers need a balance of suppliers who are prepared to sell at a lower level than us to enable a lower price on the shelf to be available in the fight against Asda. Our business with one retailer last year improved by ten percent, where their own plan was for it to grow five percent, which is reassuring for us. However, our relationship could be improved, which would lead to benefits on the shelf."

"We are in a position ourselves where no matter what happens we have a viable business, and if we are put out of business in five or ten years time we will have done what we set out to do, which was to achieve a sizeable business. We will have a very strong balance sheet, which will always be with us. We have talked to people about direct dealings. We do not talk to competitors in terms of pricing. We are fiercely independent, and without being conceited as being arrogant, we generally see ourselves as trying to do the best job, and people are continually learning from ourselves." 


\section{Table 4b. In-depth Supplier Y interview protocol, with some text evidence}

\section{Probing question}

How many years have you been involved as a supplier in the UK fresh produce industry? (Possible areas: year started, growth, multiples)

How would you describe the type of contact that you currently have with retailers? (Possible areas: daily, weekly, meetings, Internet, telephone)

What is discussed during this contact, and has technology such as Internet benefited this in any way? (Possible areas: production rates, problems, future stock requirements, exchange of ideas, transportation)

How would you describe your relationship with retailers? (Possible areas: positive, improving, collaborative)

\section{Text evidence}

"We started supplying Marks and Spencer in the late 1950's. It then evolved with Sainsbury's in the 1970's, Waitrose followed shortly afterwards, and then we got involved with the Co-Ops some thirteen years ago. We have also supplied Safeway and Asda in the last ten years."

"Daily contact, at all levels. It has really changed over the last two years. If I go back four or five years, it was generally the account manager who was talking to the multiple buyers, perhaps once or twice a week. That has changed and now you have got the multiple buyers talking to the account manager, the technical manager talking to the multiples' technical people. We are now involved as a company on so many different levels, with bench marketing coming into play, meaning we go into the stores and look at the products. We do reports that go through to the customers, which provoke conversations between the benchmarking people etc. The technical managers try to tell us how we can improve the business and cut costs. We have therefore seen a rapid movement in the communication with the multiples in the last two years. The Internet has also helped improve information exchange and contact with retailers."

"The account manager is talking on a week-to-week basis on the volume available for the forthcoming week and making sure the retailer buyer knows why we have got that volume available. We use email most weeks, with technology being particularly useful. The buyers and account managers talk about their differing needs. At the account manager stage we also have to do quite a few retail reports. Every Monday, we get a retail report from the local stores detailing what products are retailing at. This goes through to the retailer buyer from the account manager. It is all about what is happening in the market. The account manager and technical manager will discuss issues such as the crop. For example, a the moment some of our crops do not have the weight, but do have the correct size. The technical people are then asked if the weight boundaries can be reduced. Pesticide issues and residue analysis are discussed, which incidentally we do, as do the retailers. We always make sure the records are correct. All information is flowing between us and the retailers."

"It varies. The concern is that it varies depending on the individual who is in the buying chair. Until 2000, we would have a buyer for probably no more than two years maximum. It could be a year-and-a-half. They have one season under their belt, just learned what the situation is, then by the second season they are gone and you start all over again. There was a big frustration from 1995 to 2000 because you could not actually build a relationship so that the buyer knew that our strong points were $\mathrm{x}, \mathrm{y}$, and $\mathrm{z}$, and because of that would then give us bonuses - and take business away from us if we were weak in other areas, which is fair enough. That did not happen, as the buyer was changing too quickly. Just recently, the buyers have started to slow down, so it has got better. Some multiples do not change their buyers for six-seven-eight-nine years. Waitrose, for example, has a buyer whom we deal with, who has been there for six years. Before him, the previous buyer had been there a good ten years. Relationships with them are thus good." 


\section{Table 4b. In-depth Supplier Y interview protocol, with some text evidence, continued}

\section{Probing question}

What effect have the concepts of backhauling and factory gate pricing had on your business? (Possible areas: costing, pressure, relationships, haulage outlooks)
The concept of category management has seen a decline in fresh produce suppliers over time. Do you feel this trend will continue? (Possible areas: rationalization, favored suppliers, long-term and short-term effects)
What do you think are the benefits of a partnership between suppliers and retailers? (Possible areas: improved sales, better quality, improved relationship, mutuality)
Do you personally feel that you are working in a partnership with all the selected retailers? (Possible areas: recent schemes, move to certain suppliers, supplier attitudes and ideas)

If not, what are the problems that are currently arising? (Possible areas: lack of trust, cooperation, attitudes)

How do you feel your relationships can be improved with current retailers? (Possible areas: cooperation, collaboration, partnerships, improved customer satisfaction)

\section{Text evidence}

"Again, it varies depending on the supermarket. We are actually a primary consolidator, a hub in other words. We are supplying transport for many fresh produce suppliers in the area. I can answer this question in two ways.

Firstly, from a primary transport point of view it has given us slightly more work. However, the prices are being reduced. The vehicles are now moving from $\mathrm{A}$ to $\mathrm{B}$, at the lowest rates they can, and all that money is going into the multiples' pockets, and as a primary haulier it is really borderline whether it is worth doing it. We regularly question it. It is worth having the transport fleet we have. We run 23 vehicles, with 30 plus fridges. They have taken a lot of the cost out the business, which is good in some ways, but we as a primary haulier are right on the limit. A lot of people are thinking about disbanding their fleet.

From a supplier point of view, we have been fortunate in that it has not had a great affect to date. However, I do know of companies in the area whom the retailers have approached and asked what is your transport costing to get from A to B. OK, it is fifty pence. The retailers go away, find a haulier that will do it for thirty-two, the charge the fifty pence to that supplier and that 18-pence difference goes straight in the pocket of the retailer. That is adding to their profit, at the end of the year, but it is not actually helping the supply base. If the supply base is having good years, and no one is worried, both parties have to make a living that should be fine. We are having a hard, and the demands from the supermarkets have increased immensely, and it is not actually showing on the bottom line. We are getting paid less, yet still doing a lot more work. Factory gate pricing is hard and is not actually giving anything back to the supply base. Unfortunately, it is benefiting the retailer."

"Yes, I do. Waitrose are for instance one of the category leaders. Asda are also becoming inclined to deal with fewer suppliers and are using consolidator for certain fresh produce, which suppliers must go through. Naturally that has given great gains to the category leader from each product type. I would have thought that other suppliers would have lost out, but in conversation this has not actually happened. Asda are taking the least margin allowing its suppliers to benefit from a very good price. Wal-mart is paying suppliers exceptional prices at the moment. We currently do a margin policy to help us see which retailer is the best payer over a period of 12 months."

"Up until recently, I would have said that partnership is a good thing and that collaboration is a good thing. I was a very strong believer in that it was the way forward. I do not at the moment think that is the case. The multiples now are using the word partnership and want an open book policy, though not all of them. But we do have a scenario starting to prevail where they are picking certain parts of the information they want to use to actually reduce the price to the grower. The retailers do not always give you the whole picture. We have had to do the business plans for the multiples and a lot of the time only 20 percent of the information is used, and the retailers use this to tell us we are cheaper at $\mathrm{x}, \mathrm{y}$, and $\mathrm{z}$ than our competitor - therefore we are getting a better return to the field, which is wrong. We want that return. Retailers should recognize that we are cheaper and split the difference fifty-fifty. They should recognize we are giving quality and a competitive price and reward us with more business. Retailers are just taking what they want."

N/A

"The way things are looking at the moment, I think if the supermarkets did not have as much power - and so that the general consensus of opinion coming from the supermarkets was not as one sided and more of a partnership - it would be better. I am very concerned at the way this industry is moving forward, and concerned about the future." 
Table 4b. In-depth Supplier Y interview protocol, with some text evidence, continued

Probing question

What are your feelings towards the future outlook for the UK fresh produce industry? (Possible areas: rationalization, efficient suppliers, commitment)

\section{Text evidence}

"Not good at the moment. Rationalization is taking place, and in some ways that is a good thing, as it allows costs to be offset. However, there has to be a clear understanding from the buyers at the retailers and the technical people, of how the supplier and retailer can work together to improve the products being offered. In a lot of the retailers it does not seem to be coming through at this moment in time. I have just spoken to a person who is a supplier to some multiples, and he is in agreement with what I have just said. There is still a feeling with certain retailers that it is 'them, and us' and there is no trust. If you do not have trust with your supply base, stop and pull away, or try and change. Without the trust, and with factory gate pricing, I believe it will get worse." 


\section{Table 5a. In-depth Retailer X interview protocol, with some text evidence}

\section{Probing question}

How many years have you been involved as a retailer in the UK fresh produce industry? (Possible areas: year started, growth, multiples)

How would you describe the type of contact that you currently have with suppliers? (Possible areas: daily, weekly, meetings, Internet, telephone)

What is discussed during this contact, and has technology such as Internet benefited this in any way? (Possible areas: production rates, problems, future stock requirements, exchange of ideas, transportation)

How would you describe your relationship with suppliers? (Possible areas: positive, improving, collaborative)

What effect have the concepts of backhauling and factory gate pricing had on your business? (Possible areas: costing, pressure, relationships, haulage outlooks)

The concept of category management has seen a decline in fresh produce suppliers over time. Do you feel this trend will continue? (Possible areas: rationalization, favored suppliers, long-term and short-term effects)
What do you think are the benefits of a partnership between suppliers and retailers? (Possible areas: improved sales, better quality, improved relationship, mutuality)

\section{Text evidence}

"I have personally been involved in retailing for seven or eight years, and have been involved in fresh produce for about two-and-a-half years."

"With major suppliers, it is daily contact by 'phone, and the Internet is available to us and suppliers constantly for stock updates."

"We discuss forthcoming weather, the general market, how EU markets are changing. There are quite strict rules on what we can discuss. We cannot discuss retail prices. It is really about managing the day-to-day volumes, which can be very volatile. We can talk about future everything, except retail prices. We discuss expected consumer demands. We have planning routines that can be sixth monthly that we can discuss."

"The suppliers we work with and the suppliers that are dedicated or have ties with us are, I would say, in a good relationship with us. Obviously there can be difficulties and issues, such as suppliers supplying a number of retailers, and we will not deal as keenly with them, as we would suppliers who are dedicated to us and who are trying to make us the key winner. There have been implementations recently, whereby for example Asda has selected category suppliers, and the result has been we have lost those suppliers, not because of us but through their own choice. We have therefore tended to develop stronger relationships with suppliers who want to supply us.'

"Effectively what we do know is that the amount of haulage that we do will enable the backhauling concept and factory gate pricing to give us very good haulage rates. At the moment, everyone benefits from those rates. By doing our own haulage we can negotiate our rates and benefit from the very large volumes of fresh produce we currently deal with. However, the effect on buying level at the moment is minimal. We do not get involved with distribution costs that are being managed by a factory gate pricing team. All factory gate pricing is doing is taking the cost out the companies' main haulage, and consolidations are being chosen to help us with our haulage. It is generally just helping to take the costs out of the haulage bill for everybody. At the end of the day, the product still costs the same; it is just that suppliers will be paying less for haulage. It should allow us in the medium term to increase the amount of volume we deal with."

"I think it has been pretty stark over the last five years in fresh produce, but we are now at a stage where we are dealing with the best, and as a result there is not a lot more consolidation to go on. There are no plans for us to do what Asda have done at the moment, and I think it is fair to say that their suppliers are struggling to meet their demands. We are not planning to do this at all. We have reduced our supplier base and gained a lot of cost benefits as a result of this."

"With there being fewer suppliers the ones supplying us are tending to supply us with more fresh produce over time. It is difficult to have a situation where they supply you purely because there comes a day when you cannot take everything they have. We know they have to go to other people and we are flexible about this, but do expect them to prioritize us if we are finding fresh produce sourcing difficult."

"It is key to us in terms of quality, service, and price, to our customers, and we cannot do that without the strengths and excellence of our supply base. Without that we would struggle completely. The suppliers, I would like to think, know what is going on, the areas that we are looking to improve, and in general the relationships are good. We take into account hard times such as disease in crops and a shortage of crops due to the weather, and gear ourselves up accordingly. We try to support British farmers where possible and have a strategy of local fresh produce to local stores. Last year, we sourced 95 percent of our soft fruit from British suppliers in summer season, and try to retain to retain a reasonable rate of return for the British supplier, as well." 


\section{Table 5a. In-depth Retailer X interview protocol, with some text evidence, continued}

\section{Probing question}

Do you personally feel that you are working in a partnership with all the selected suppliers? (Possible areas: recent schemes, move to certain suppliers, supplier attitudes and ideas)

If not, what are the problems that are currently arising? (Possible areas: lack of trust, cooperation, attitudes)

How do you feel your relationships can be improved with current suppliers? (Possible areas: cooperation, collaboration, partnerships, improved customer satisfaction)

What are your feelings towards the future outlook for the UK fresh produce industry? (Possible areas: rationalization, efficient suppliers, commitment)

\section{Text evidence}

"I think in many areas the key suppliers we work with are working very well. They are providing us with what we require. The issues you often hear about, we do not necessarily deal with in fresh produce, and there are suppliers out there not making money because they lack efficiency. We tend to work with larger suppliers who are successful. We like to see investment from suppliers. I do not see that we have any specific problems with suppliers, and our relationship will always be one of discussions, discussing prices and volumes, and, as I have said, there are difficult times, but generally we are happy with the suppliers we deal with. That is why we deal with them, and I think they are happy with what they get from us."

"All information is available to the supplier apart from the gross margins, which they can work out anyway from their cost price and the retail price of the product. I think, as we have reduced our supplier base, we have worked closer with those suppliers and they come back to us with suggestions on how to build customer loyalty, and how to market products. We have got much closer, and the idea of category management is that suppliers help run the category. We are not quite the same as Asda in that respect, as we want to retain some control of our business, but still have a strong relationship."

"I think it is fair to say that there have been changes in the last five years, with some big winners, but also some big losers. Those that have done well have done very well. It is the same with the retailers, some have done well, but those that do not do a very good job have fallen by the wayside. I think if those successful suppliers who supply the more successful retailers continue doing so then they have a very bright outlook. Without doubt training people up is key to fresh produce and supplier success. The key challenge at the moment to the fresh produce industry is Asda and its low pricing policy that is affecting everyone in the fresh produce industry, with all retailers trying to remain competitive, whilst also keeping quality levels high. Quality, service, and price are the three key issues that we are constantly trying to meet." 


\section{Table 5b. In-depth Retailer Y interview protocol, with some text evidence}

\section{Probing question}

How many years have you been involved as a retailer in the UK fresh produce industry? (Possible areas: year started, growth, multiples)

How would you describe the type of contact that you currently have with suppliers? (Possible areas: daily, weekly, meetings, Internet, telephone)

What is discussed during this contact, and has technology such as Internet benefited this in any way? (Possible areas: production rates, problems, future stock requirements, exchange of ideas, transportation)

How would you describe your relationship with suppliers? (Possible areas: positive, improving, collaborative)

What effect have the concepts of backhauling and factory gate pricing had on your business? (Possible areas: costing, pressure, relationships, haulage outlooks)

The concept of category management has seen a decline in fresh produce suppliers over time. Do you feel this trend will continue? (Possible areas: rationalization, favored suppliers, long-term and short-term effects)

What do you think are the benefits of a partnership between suppliers and retailers? (Possible areas: improved sales, better quality, improved relationship, mutuality)

Do you personally feel that you are working in a partnership with all the selected suppliers? (Possible areas: recent schemes, move to certain suppliers, supplier attitudes and ideas)

If not, what are the problems that are currently arising? (Possible areas: lack of trust, cooperation, attitudes)

How do you feel your relationships can be improved with current suppliers? (Possible areas: cooperation, collaboration, partnerships, improved customer satisfaction)

What are your feelings towards the future outlook for the UK fresh produce industry? (Possible areas: rationalization, efficient suppliers, commitment)

\section{Text evidence}

"Myself personally, one year in fresh produce, but working for this specific retailer about seven or eight years."

"Daily contact with twelve major suppliers by 'phone and several face-toface meetings four times a week. The Internet is available for information, but most information is discussed by 'phone."

"There are two types of meeting, day-to-day meetings, which we are probably looking three weeks ahead and at the retail price strategy, and long-term meetings in which we are probably looking at any period from three months to twenty-four months. This is more to do with the planning with the grower."

"I think it is a very close relationship, and we get on well with our suppliers."

"We have a number of projects going to do with the subject, but they are quite low key, as we do not tend to chop and change our suppliers. We have probably been with some suppliers for decades. We look at changes such as factory gate pricing and backhauling as a medium-term thing, and tend to look as the marketplace. We tend to observe, then adapt, but progress is being made. Certainly we are looking at it, and weighting up the options carefully."

"I think it will. I am not sure if in the longer run it will be in the best interests of the industry. It needs to be assessed over a period of time. There is the problem of being able to guarantee consumers the volumes they expect. I expect in the next two-to-three years there will be further rationalization. We will not follow in the style of retailer such as Asda and will look at possible problems with suppliers."

"From the supplier's point of view it gives confidence, security. There is a guarantee with a small grower. The business is going to benefit from this, with good returns etc. From the retailer's point of view, we would develop stronger links with our supply base, and develop the relationship. You work together to help drive up sales of fresh produces. Suppliers and us work together to achieve sales."

"There is cooperation with all of them, but not collaboration with them all. Those we feel we collaborate with more we will reward in terms of volume. We will use suppliers who want to collaborate with us."

"Where do you start? People - the fresh produce industry is not renowned for attracting the best caliber of people sometimes. We are lucky in some respects. Our suppliers on the whole are good to work with, but the caliber of people could be improved in some cases. Some do not want to listen and are arrogant."

"I think we need to do the long-term planning better together. I still think there are weaknesses in this. I think substantial improvements to this are could benefit product sales. I think we are pretty open with our suppliers, as regards product sales and they have access to lots of data pretty quickly. Building the trust and getting better visibility is something that needs to be worked at in the food supply industry. Trust always needs to be there between the supplier and retailer. It does not help the job when retailers move buyers on. Some of us buyers have been here for eight years. The same goes for the technologists - some of them have been here five-six-seven years and it helps the relationship. It would frustrate me, as a buyer, if I had to move after just a year, as I have just started to get to know how some of our suppliers work."

"The outlook has to be good. For example fruit - I work with fruit, and I think the potential for it is immense. There will be fewer suppliers, but there is a lot of money to be made in fresh produce and they know that. If they get their business right, their relationships with us will grow. The future is bright. I do not think it is rosy, but if I was a good supplier I would be reasonably optimistic about the future. 


\section{Table 6. In-depth haulier interview protocol, with some text evidence}

\section{Probing question}

How many years have you been involved as a haulier in the UK fresh produce industry? (Possible areas: year started, growth, multiples)

How would you describe the type of contact that you currently have with suppliers and retailers? (Possible areas: daily, weekly, meetings, Internet, telephone)

What is discussed during this contact, and has technology such as Internet benefited this in any way? (Possible areas: production rates, problems, future stock requirements, exchange of ideas, transportation)

How would you describe your relationship with suppliers and retailers? (Possible areas: positive, improving, collaborative)

What effect have the concepts of backhauling and factory gate pricing had on your business? (Possible areas: costing, pressure, relationships, haulage outlooks)

The concept of category management has seen a decline in fresh produce suppliers over time. Do you feel this trend will continue? (Possible areas: rationalization, favored suppliers, long-term and short-term effects)

What do you think are the benefits of a partnership between suppliers, retailers, and hauliers? (Possible areas: improved sales, better quality, improved relationship, mutuality)

Do you personally feel that you are working in a partnership with all the selected suppliers and retailers? (Possible areas: recent schemes, move to certain suppliers, supplier attitudes and ideas)

If not, what are the problems that are currently arising? (Possible areas: lack of trust, cooperation, attitudes)

How do you feel your relationships can be improved with current suppliers and retailers? (Possible areas: cooperation, collaboration, partnerships, improved customer satisfaction)

What are your feelings towards the future outlook for the UK fresh produce industry? (Possible areas: rationalization, efficient suppliers, commitment)

\section{Text evidence}

"Since 1986 with major retailers, but a few years before with suppliers."

"Daily with major retailers, with the same for certain suppliers. The Internet is used, with e-mail as well, though contact is still very much based on face-to-face interviews and telephone conversations."

"At basic level, we discuss delivery points, collection schedules, load formats - the list is quite large. Moving on from this, managers discuss transport problems, problems the retailers and suppliers are having, and solutions or new ideas to strengthen the supply chain. Directors meet and discuss the way the company is going and changes that they would like to see."

"I think our relationships are positive, with a need to get along important for business relations."

"We had long been expecting backhauling and factory gate pricing so the change was anticipated. Clearly both processes help reduce supply chain costs and efficiency and have enabled reduced distances for product movement to be achieved."

"Suppliers are reducing, though we nowadays have little to do with suppliers in terms of financial or commercial aspects. It is more related to the retailer. We merely collect from designated suppliers for later delivery to the retailers."

"Clearly in our case the benefits are chiefly volume and critical mass, which can only be achieved by working together. I think our relationship varies by degree, with the power ultimately in the hands of the retailer. We work with them, as we have a requirement to help them run the transport system as efficiently as possible. We have the expertise in areas they do not and so work with them to put this expertise into practice to benefit the supply chain."

"We could improve collaboration partly, but chiefly the best way to improve our relationship is to have involvement from all parties, as early as possible. This way, problems can be solved more easily and costs saved in the long term. By allowing this to occur greater decisions can be made and reached with significant gains to the supply chain."

"I think there will be a further reduction in suppliers, though for the most part it has now slowed down considerably. I think that there will be more suppliers joining together, forming cooperatives and making stronger trading companies. In haulage terms, fleets will be joining together from different companies, both primary and secondary, and cost reduction and profit maximization will be the key aims of these companies." 